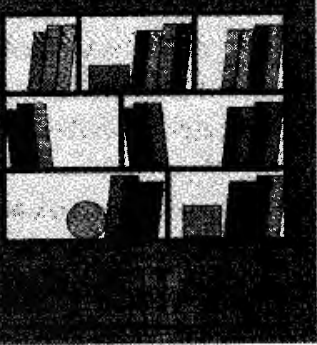

\title{
ANÁLISE DAS VARIAÇÕES NO LUCRO BRUTO SOBRE VENDAS
}

* Ivan Pinto Dias

A determinação das causas da variação no lucro bruto sobre vendas de dois períodos de tempo obriga a uma análise das causas das variações nas vendas e no custo das mercadorias vendidas.

The determination of the causes of variation on gross profit over sales concerning two periods of time demands an analysis of variations on sales and cost of goods sold.

PALAVRAS-CHAVE:

Vendas, lucro bruto, variâncias, preço de venda unitário, custo unitário, volume (quantidade), demonstração, gráficos.

\section{KEY WORDS:}

Sales, gross profit, variances, quit selling price, unit cost, volume (quantity), statements, graphs.
* Professor Emérito e ex-Professor Titular do Departamento de Contabilidade, Finanças e Controle da EAESP/FGV.

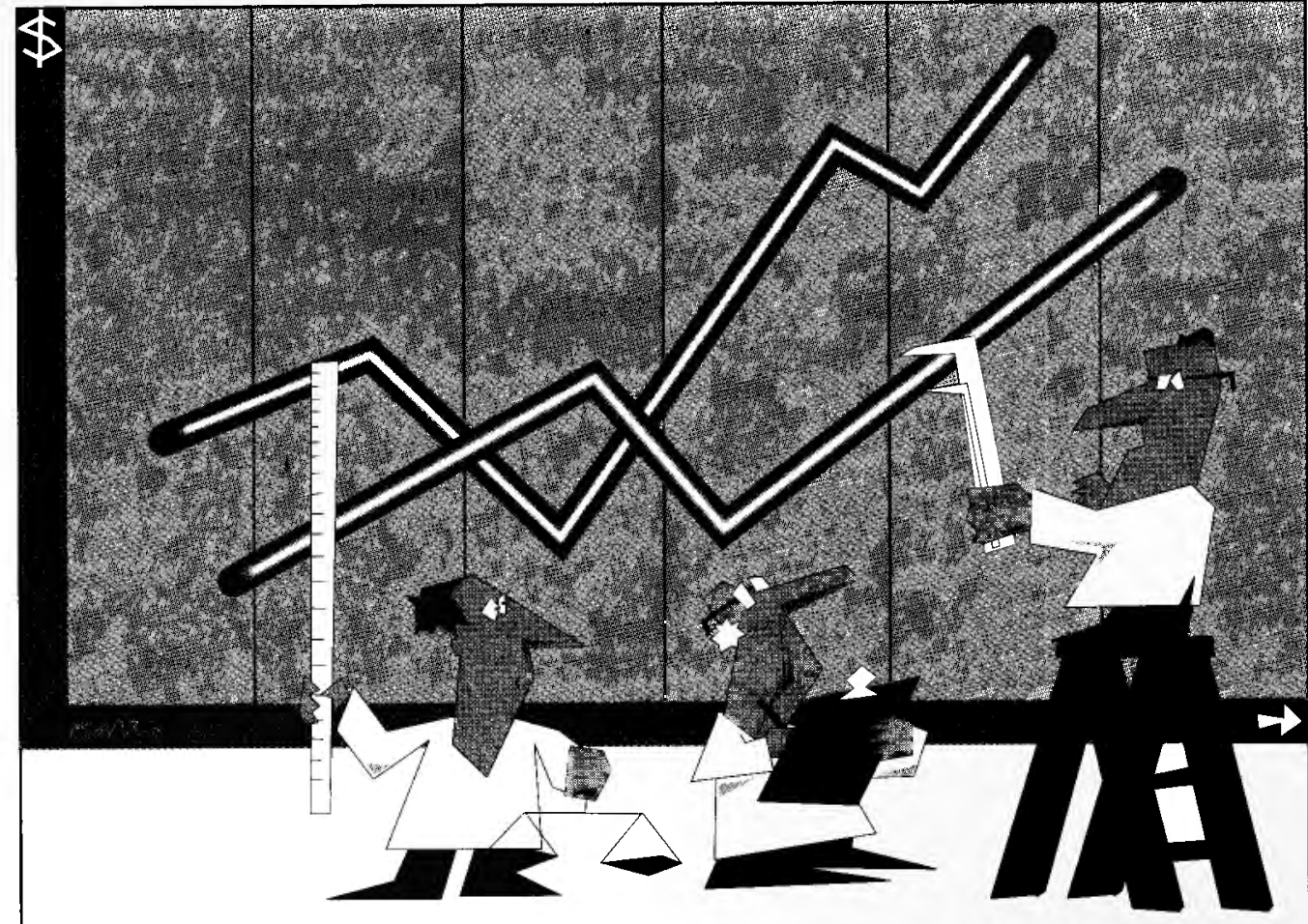

"A determinação das causas da variação no lucro bruto sobre vendas de dois períodos de tempo obriga a uma análise das causas das variações nas vendas e no custo das mercadorias vendidas."

G. A. Welsch, C. T. Zlatkovich e J. A. White. 
1. Os interessados nesse problema poderão consultar, por exemplo: Techniques for Effective Reporting to Management. In: NAA Bulletin, National Association of Accountants, New York, fevereiro, 1952, seção 1; Presenting Accouting Information to Management. In: NAA Bulletin-Research Series n. 28, dezembro, 1954; Reporting Data to Top Management. In AMA Special Report n. 25, American Management Association, New York, 1957; Reports Which Management Find Most Useful. In: NAA Bulletin - Accouting Practice Report n. 9, fevereiro, 1960, seção 3; LEWIS, R. B. Accouting Reports for Management, Englewood Cliffs: Prentice-Hall, Inc., 1957; e Financial Analysis for Management, Englewood Cliffs: Prentice-Hall, inc., 1959

2. Utilizamo-nos propositadamente, para esse exemplo, dos dados constantes do artigo Análise das Variações no Lucro Líquido, Revista de Administração de Empresas, v. 6, n. 20 , set. 1966, p. 41 a 58 . Consultando 0 artigo mencionado, 0 leitor verificará que é interessante obter primeiro a explicação das razōos da alteração do ucro líquido de um período para outro, para depois nos concentrarmos nos aspectos do lucro bruto sobre vendas. Como os dados numéricos são iguais somente acrescidos de mais algumas informações, fica bem mais fácil 0 entrosamento desses dois tipos de análises.

3. Um mark-up sobre vendas de $60 \%$ pode ser representado genericamente pela seguinte situação:

Vendas líquidas .............. 100\%

(-) Custo das Mercadorlas

Vendidas........................... 40

Lucro Bruto

sobre Vendas.................... $60 \%$

Para se obter o mark-up sobre 0 custo, faz-se 0 custo das mercadorias vendidas igual a $100 \%$, isto ê $60 \%=150 \%$ e, portanto:

$40 \%$

Vendas Líquidas ................ 250\%

(-) Custo das

Mercadorias

Vendidas......................... 100

Lucro Bruto

sobre Vendas.................. 150\%
O diretor financeiro de uma empresa afirmou certo dia, em reunião de diretoria: "Nossas vendas aumentaram no ano passado 50\%, enquanto que o lucro bruto sobre essas vendas caiu em $17 \%$ ". O presidente da empresa, apoiado por alguns diretores - principalmente o de vendas -, respondeu que isso era impossível e devia haver "erro nos dados".

O diretor financeiro viu-se em apuros para explicar como isso ocorrera, pois nem o presidente nem os outros diretores eram muito versados em matéria de administração contábil e financeira. Foi tão grande o problema de comunicação daí decorrente, que durante muito tempo não se falava em outra coisa na empresa.

Isso talvez não constitua novidade, pois aqueles que labutam na administração contábil e financeira das empresas estão entre os que mais sentem problemas de comunicação. Algumas vezes isso ocorre por deficiência desses mesmos administradores, quando, por exemplo, empregam terminologia difícil ou complicada, ou apresentam relatórios que mais ninguém entende e, no entanto, se destinam a leigos no assunto que necessitam compreendê-los. ${ }^{1}$

Num país como o nosso, sujeito constantemente a maior ou menor ritmo de inflação e ainda não de todo desenvolvido, e numa época em que são muitos e nítidos os controles exercidos pelo governo sobre a empresa privada - como os da legislação fiscal, no sentido, por exemplo, de estimular a contenção de preços -, torna-se mais importante ainda a questão de saber porque houve variação no lucro bruto sobre vendas de um período para outro e explicar como isso ocorreu.

Neste artigo procuraremos mostrar de que forma isso pode ser feito, levando sempre em consideração, na medida do possível, o aspecto de comunicação do problema.

Empregaremos exemplos numéricos simplificados, com percentagens e/ou índices arredondados, a fim de possibilitar melhor compreensão dos princípios a serem expostos. Alguns dos tópicos ou demonstrações apresentados são já conhecidos em outros países, porém, ao que tudo indica, a literatura especializada nacional ainda não tratou dessa questão. Somos de opinião que já tarda a discussão em nosso idioma de tão importante problema e é por essa razão que abordamos o assunto, com a esperança de incentivar o debate que, principalmente com as críticas e sugestões dos leitores, poderá aclarar ou aprofundar a análise feita.

\section{CASO DA COMPANHIA ALFA}

Imaginemos o caso da companhia Alfa, que apresenta as seguintes informações: ${ }^{2}$

\begin{tabular}{|c|c|c|c|c|}
\hline \multirow{3}{*}{ Vendas Líquidas.... } & \multicolumn{2}{|r|}{$19 \times 1$} & \multicolumn{2}{|r|}{$19 \times 2$} \\
\hline & $\mathrm{Cr} \$$ & $\begin{array}{r}1.000 .000 \\
400.000 \\
\end{array}$ & Cr\$ & $\begin{array}{l}1.500 .000 \\
1.000 .000\end{array}$ \\
\hline & Cr\$ & 600.000 & Cr\$ & 500.000 \\
\hline
\end{tabular}

São conhecidos ainda os seguintes dados:

\begin{tabular}{|c|c|c|c|c|}
\hline \multirow{3}{*}{ 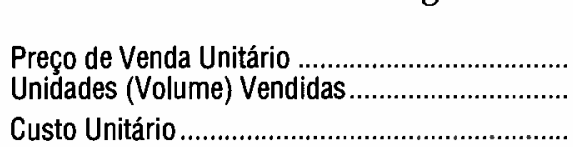 } & \multicolumn{2}{|c|}{$19 \times 1$} & \multicolumn{2}{|c|}{$19 \times 2$} \\
\hline & $\mathrm{Cr} \$$ & $\begin{array}{l}100 \\
.000 \\
\end{array}$ & Cr\$ & $\begin{array}{l}120 \\
.500 \\
\end{array}$ \\
\hline & $\operatorname{Cr} \$$ & 40 & $\mathrm{Cr} \$$ & 80 \\
\hline
\end{tabular}

A análise vertical e horizontal da primeira parte das informações daria o resultado a seguir:

\begin{tabular}{|c|c|c|c|c|c|c|c|}
\hline & \multicolumn{2}{|c|}{$19 \times 1$} & \multicolumn{2}{|c|}{$19 \times 2$} & $\begin{array}{l}\text { Aumento (ou } \\
\text { diminuição) }\end{array}$ & $\begin{array}{l}\text { Aumento (ou } \\
\text { diminuição) }\end{array}$ & $\begin{array}{l}\text { Índice de } 19 \times 2 \mathrm{em} \\
\text { relação a } 19 \times 1\end{array}$ \\
\hline & $\mathrm{Cr} \$$ & $\%$ & $\mathrm{Cr} \$$ & $\%$ & $\mathrm{Cr} \$$ & $\%$ & \\
\hline Vendas Liquidas & 1.000 .000 & 100 & 1.500 .000 & 100 & 500.000 & 50 & 1,5 \\
\hline $\begin{array}{l}\text { (-) Custos das Merca- } \\
\text { dorias Vendidas }\end{array}$ & 400.000 & 40 & 1.000 .000 & 67 & 600.000 & 150 & 2,5 \\
\hline sobre Vendas & 600.000 & 60 & 500.000 & 33 & $(100.000)$ & (17) & 0,8 \\
\hline
\end{tabular}


Uma forma, portanto, de responder ao presidente e aos diretores mencionados no início deste artigo seria mostrar que as vendas líquidas aumentaram $50 \%$, enquanto que o custo das mercadorias vendidas se elevou em $150 \%$ (ou é igual a 2,5 vezes, conforme indica a coluna dos índices de 19x2 em relação a 19x1), resultando uma diminuição de $17 \%$ no lucro bruto sobre vendas, uma vez que esse representava $60 \%$ das vendas em 19x1 e em 19x2 representa apenas 33\%, ou seja, em 19x2 é apenas 0,8 vezes o de $19 \times 1$.

Essa explicação, porém, não diz tudo, pois a análise horizontal do restante das informações mostra o que se segue.

\begin{tabular}{lc|c|c|cc}
\hline & $19 \times 1$ & $19 \times 2$ & $\begin{array}{c}\text { Aumento (ou } \\
\text { diminuição) }\end{array}$ & $\begin{array}{c}\text { Aumento (ou } \\
\text { diminuiçãa) }\end{array}$ & $\begin{array}{c}\text { Índice de 19x2 em } \\
\text { relação a 19x1 }\end{array}$ \\
\hline $\begin{array}{l}\text { Preço de Venda } \\
\text { Unitário }\end{array}$ & $\mathrm{Cr} \$ 100$ & $\mathrm{Cr} \$ 120$ & $\operatorname{Cr} \$ 20$ & 20 & 1,20 \\
$\begin{array}{l}\text { Unidades Vendidas } \\
\text { Custo Unitário }\end{array}$ & 10.000 & 12.500 & 2.500 & 25 & 1,25 \\
\cline { 2 - 6 } & $\mathrm{Cr} \$ 40$ & $\operatorname{Cr} \$ 80$ & $\operatorname{Cr} \$ 40$ & 100 & 2,00 \\
\hline
\end{tabular}

Percebe-se, portanto, que o preço de venda unitário aumentou $20 \%$, enquanto que o custo unitário elevou-se em $100 \%$ (sendo, em $19 \times 2,2,0$ vezes a quantia de $19 \times 1$ ); ao mesmo tempo, foram vendidos mais $25 \%$ de unidades do produto fabricado pela Companhia Alfa.

Para maior clareza mostramos esses resultados nos gráficos 1 e 2 .

Ainda assim, não ficou claro o porquê da variação no lucro bruto sobre vendas de um período para outro.

Não devemos esquecer que a percentagem do lucro bruto sobre vendas - ou o markup sobre vendas - de $60 \%$ em $19 \times 1$ equivale a um mark-up sobre custo - percentagem adicionada ao custo para se obter o preço de venda de modo que haja uma taxa fixa de lucro bruto sobre vendas - de $150 \%{ }^{3}$ Uma vez que o mark-up sobre vendas foi em $19 \times 2$ de apenas $33 \%$, o mark-up sobre custo baixou para apenas $50 \%{ }^{4}$

Em outras palavras, em 19x1 acrescentavam-se $150 \%$ ao custo dos produtos para se obter o preço de venda, enquanto que em $19 \times 2$ somaram-se somente $50 \%$.

Obtivemos, portanto, percentagens e índices que, apesar de serem elucidativos, podem dar azo a dúvidas - principalmente de parte de leigos no assunto - em especial se nos lembrarmos dos cuidados a serem tomados na análise vertical e horizontal. ${ }^{5}$

Isso torna necessário encontrar-se um modo melhor de solucionar o problema.

\section{ANÁLISE COM DUAS VARIÁVEIS}

O lucro bruto sobre vendas é o resultado das vendas líquidas menos o custo das mercadorias vendidas. Fazendo primeiro uma análise das variações nas vendas líquidas e depois das variações no custo das mercadorias vendidas, talvez possamos explicar melhor por que e como variou o lucro bruto sobre vendas.

\section{Variações em vendas}

As vendas líquidas variam de um período para outro em função de dois fatores volume (ou quantidade) de mercadorias transacionadas e preço de venda unitário. A variação decorrente da alteração no volume é calculada considerando-se o volume como sendo variável e o preço de venda unitário como constante, isto é:

\footnotetext{
Variável: aumento nas unidades vendidas 2.500 (x)

Constante: preço de venda unitário de $19 \times 1$

Cr\$ 100 $\operatorname{cr} \$ 250.000$

Obtém-se, assim, a variação decorrente da alteração do volume que representa o efeito, sobre a receita de vendas da variação no volume de unidades vendidas de 19x2 em relação a $19 \times 1 .^{6}$
}

No caso da Companhia Alfa, em que o custo unitário era de Cr\$ $40 \mathrm{em}$ $19 \times 1$, se se desejar um mark-up sobre vendas de $60 \%$, basta fazer o cálculo:

$\mathrm{Cr} \$ 40+150 \%=$

$\operatorname{Cr} \$ 40+\operatorname{Cr} \$ 60=\operatorname{Cr} \$ 100$

Logo, Cr\$100 será o preço de venda para obter-se a percentagem desejada de lucro bruto sobre vendas.

4. A linha de raciocínio da nota anterior é seguida para o ano 19x2, em que o mark-up sobre vendas é de $33 \%$, pois:

Vendas Líquidas .............. 100\%

(-) Custo das Mercadorias

Vendidas ............................ 67

Lucro Bruto

sobreVendas ................... $33 \%$

Conseqüentemente, o mark-up sobre custo, fazendo-se o custo das mercadorias vendidas igual a $100 \%$, será igual a $\frac{33 \%}{67}=50 \%$, e portanto:

Vendas Líquidas ..........
Custo das Mercadorias

(-) Custo das Mercadorias

Lucro sobre Vendas .........

Uma vez que nesse ano o custo unitário é de Cr\$80, temos:

$\operatorname{cr} \$ 80+50 \%=\operatorname{Cr} \$ 80+\operatorname{Cr} \$ 40=$ Cr\$ 120.

Em outras palavras, Cr\$120 é o preco de venda unitário que proporciona um lucro bruto sobre vendas de $33 \%$.

5. Não se deve esquecer que as alterações nas percentagens da análise vertical são afetadas por alterações nos itens que estão sendo medidos e na própria base, como, por exemplo, por modificações no lucro bruto sobre vendas e nas próprias vendas líquidas. Além disso, as alterações nas percentagens ou nos índices de análise horizontal, sem levar em consideração a inflação, devem ser interpretadas com 0 auxílio de informações suplementares. Assim, para ilustrar a questão, se as vendas líquidas aumentaram $50 \%$ - como ocorreu na empresa Alfa - isso não significa necessariamente que seja satisfatório que o lucro bruto sobre vendas tenha aumentado também $50 \%$, pois há necessidade de determinar-se quantas unidades foram vendidas em um período e no outro etc. Os apreciadores de cálculos baseados em percentagens e índices podem consultar a excelente obra de D. HUFF: How to Lie with Statistics, New York: W. W. Norton and Company, 1954.

6. Outra forma de obter esse resultado seria:

Volume vendido em $19 \times 2$ ao preço de $19 \times 1$ $(12,500 \times \mathrm{Cr} \$ 100)$

........................... Cr\$1.250.000

(-) Volume vendido

em $19 \times 1$ ao

preço de 19x1

$(10.000 \times \mathrm{Cr} \$ 100)$

............................. 1.000 .000 $\mathrm{Cr} \$ 250.000$ 


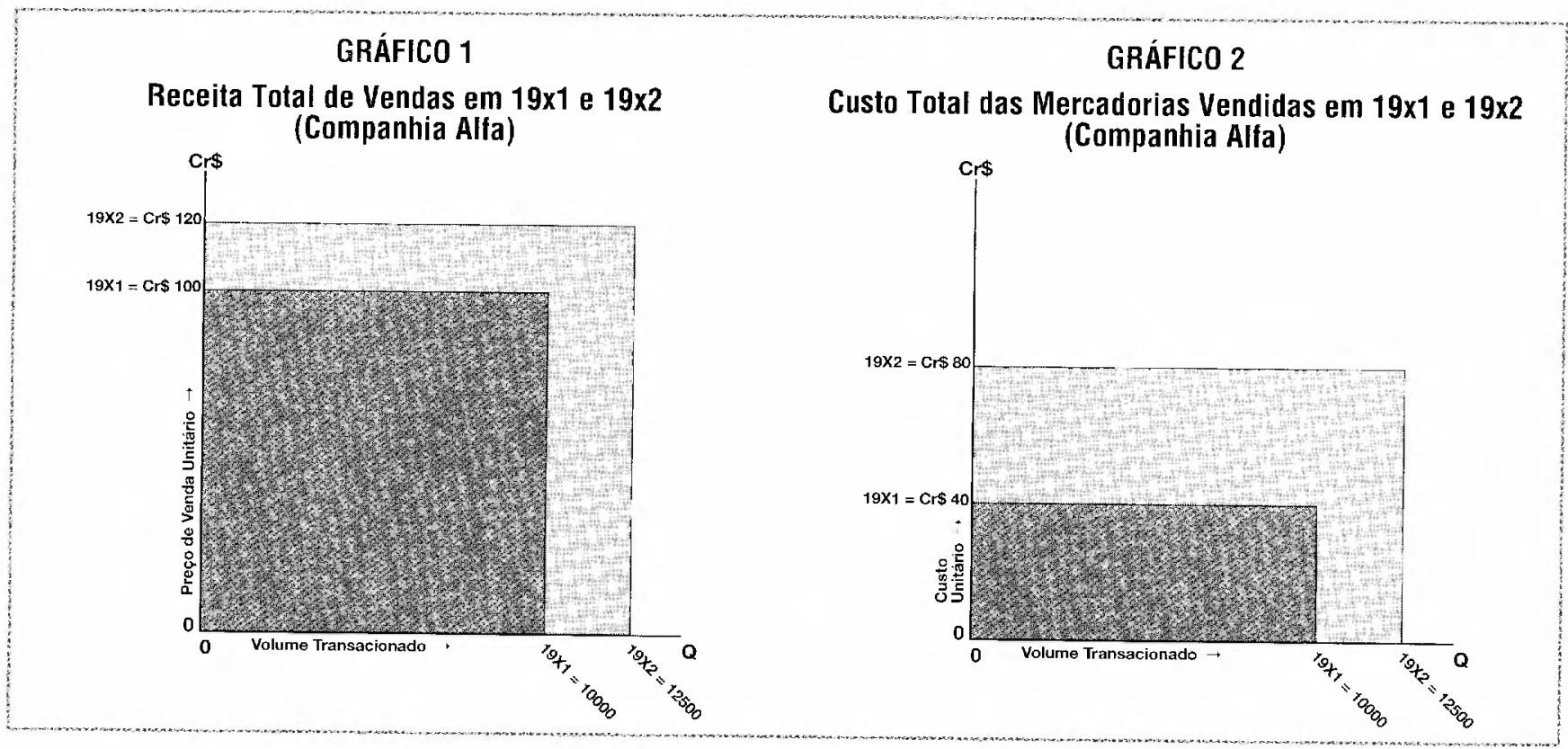

A variação decorrente da alteração no preço de venda unitário é obtida considerandose o preço de venda unitário como sendo variável e o volume como constante, ou seja:

Variável: aumento no preço de venda unitário

$\operatorname{Cr} \$ 20$

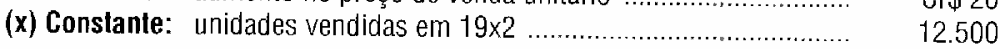

$\operatorname{Cr} 250.000$

Conseqüentemente, a variação decorrente da alteração no preço de venda unitário representa o efeito sobre a receita de vendas, da variação no preço de venda unitário de $19 \times 2$ em relação a $19 \times 1 .^{7}$

Já foi, portanto, possivel explicar que as causas do aumento de Cr\$ 500.000 nas vendas de $19 \times 2$ em relação a 19x1 foram as seguintes:

- Variação decorrente de alteração no volume (elevação das

vendas em virtude de aumento nas unidades vendidas)

- Variação decorrente de alteração no preço de venda unitário

$\operatorname{Cr} \$ 250.000$

(elevação das vendas em virtude de aumento do preço de venda unitário) 250.000

7. O mesmo resultado é conseguido mediante o seguinte raciocínio:

- Variação em vendas (aumento)

$\$ 500.000$

No gráfico 3 pode ser visualizada essa explicação.

em $19 \times 2$ ao preço

de $19 \times 2$

$(12500 \times(\mathrm{r} \$ 120)$

........................ $\$ 1500000$

(-) Volume vendido

em $19 \times 2$ ao

preço de 19x1

$(12.500 \times \mathrm{Cr} 100)$

$\frac{1250.000}{\operatorname{Cr} \$ 250.000}$

B. Consegue-se a mesma quantia de variação, através do seguinto cálcula:

Volurne vendido

crn $19 \times 2$ ao

custo de $19 \times 1$

$(12.500 \times \operatorname{cr} \$ 40)$

Gi\$ 500.000

(-) Volunke vendido

en $19 \times 1$ au

custo de $19 \times 1$

$(0.000 \times \operatorname{Cr} \$ 40)$

$\frac{400000}{0.000}$

$\operatorname{cr} \$ 100.000$

$(\mathbf{x})$

Variável: aumento no custo unitário

Variação no custo das mercadorias vendidas

Pode-se afirmar que o custo das mercadorias vendidas varia também em função de dois fatores - volume (ou quantidade) de mercadorias transacionadas e custo unilărio.

A variação decorrente da alteração no volume é calculada considerando-se o volume como sendo variável e o custo unitário como constante, isto é:

$(\mathrm{x})$

Variável: aumento nas unidades vendidas

2.500

Constanle: custo unitário de 19x1

$\operatorname{Cr} \$ 40$ $\operatorname{Cr} \$ 100.000$

Essa ć a variação decorrente da alteração no volume que representa o efeito, sobre o custo das mercadorias vendidas, da variação no volume de unidades vendidas de $19 \times 2$ em relação a $19 \times 1$.

A variação decorrente da alteração no custo unitário é obtida considerando-se o custo unitário como sendo variável co volume como sendo constante, ou scja: 2.500 $\operatorname{Cr} \$ 500.000$ 
GRÁFICO 3

Análise Simplificada das Variações nas Vendas (Companhia Altá)

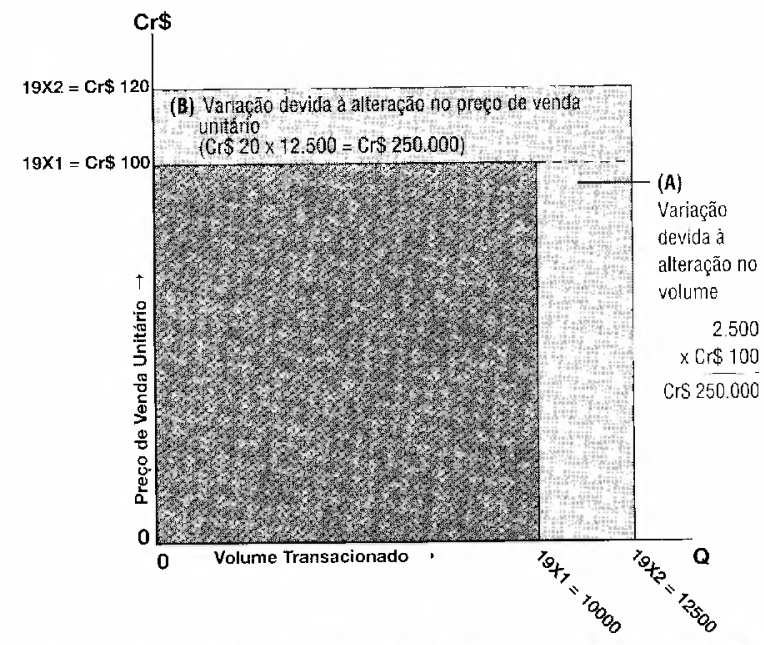

GRÁFICO 4

Análise Simplificada das Variações no Custo das Mercadorias Vendidas (Companhia Alia)

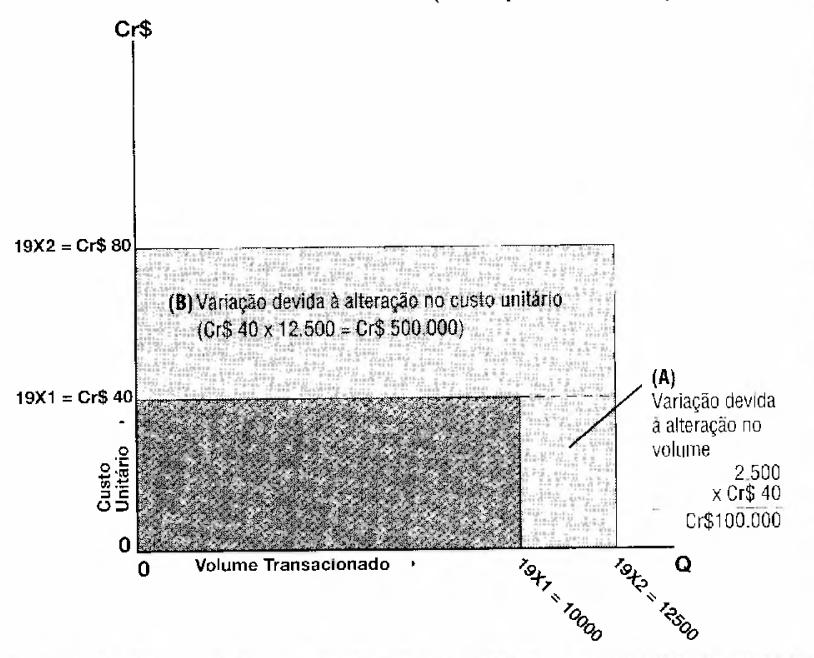

Conseqüentemente, a variação decorrente da alteração no custo unitário representa o efeito, sobre o custo das mercadorias vendidas, da variação no custo unitário de $19 \times 2$ em relação a $19 \times 1 .{ }^{9}$

Explicamos, desse modo, as causas do aumento de Cr $\$ 600.000$ no custo das mercadorias vendidas de $19 \times 2$ em relação a $19 \times 1$. Foram elas:

- Variação decorrente de alteração no volume (elevação do custo das mercadorias vendidas em virtude de aumento nas unidades vendidas)

- Variação decorrente de alteração no custo unitário (elevação do custo das mercadorias vendidas em virtude do aumento das unidades vendidas)

$\operatorname{cr} \$ 100.000$

- Variação no custo das mercadorias vendidas (aumento)

O gráfico 4 permite visualizar essa solução.

Neste ponto, seria conveniente reunir essas informações num único quadro. A nosso ver, porém, esse trabalho não compensa, pois a interpretação feita com duas variáveis volume e preço de venda unitário para as vendas, volume e custo unitário para o custo das mercadorias vendidas - é falha porque não leva em consideração outras importantes informações: a variação decorrente de alterações tanto no volume como no preço de venda unitário (no caso da análise das vendas) e a causada por alterações tanto no volume como no custo unitário ) no caso da análise do custo das mercadorias vendidas).

$\mathrm{Na}$ análise das variações em vendas, essa outra variável significa, no caso da Companhia Alfa, maior aumento da receita de vendas, em virtude do efeito simultâneo de maior volume de unidades vendidas e de elevação do preço de venda unitário. $\mathrm{Na}$ análise das variações no custo das mercadorias vendidas, a variação causada por alteraçōes tanto no volume como no custo unitário representa, no caso em questão, maior aumento no custo das mercadorias vendidas, pelo efeito simultâneo de maior volume de unidades vendidas e de elevação no custo unitário.

Assim, apesar da maior complexidade trazida ao problema por essa variável, somos obrigados a aperfeiçoar nossa explicação.

\section{ANÁLISE COM TRẼS VARIÁVEIS}

$\Lambda$ fim de facilitar a melhor compreensão da questão, vejamos, em primeiro lugar, como são obtidas as variações em vendas e no custo das mercadorias quando trabalhamos com três variáveis. Posteriormente, aplicaremos a explicação feita aos dados da Companhia Alfa.
9. Outro modo de calcular-se essa variação é:

\begin{tabular}{|c|c|}
\hline $\begin{array}{l}\text { Volume vendido } \\
\text { em } 19 \times 2 \text { ao } \\
\text { custo de } 19 \times 2 \\
(12.500 \times \operatorname{crs} 80)\end{array}$ & 1.000 .000 \\
\hline $\begin{array}{l}\text { Volume vendido } \\
\text { em } 19 \times 2 \text { ao } \\
\text { custo de } 19 \times 1 \\
(12.500 \times \operatorname{Cr} \$ 40)\end{array}$ & \\
\hline & $\frac{500.000}{500.000}$ \\
\hline
\end{tabular}




\section{Análise das variações em vendas}

a. Variação decorrente de alteração no volume: é obtida supondo-se que não tenha havido alteração no preço de venda unitário e multiplicando-se a variação no volume pelo preço de venda unitário do ano anterior (ou uma média desses preços no ano). $\mathrm{O}$ resultado é aumento ou diminuição nas vendas, dependendo de ter o volume aumentado ou diminuído.

b. Variação decorrente de alteração no preço de venda unitário: é obtida supondo-se que não tenha havido alteração no volume e multiplicando-se a variação no preço de venda unitário pelo volume do ano anterior. $\mathrm{O}$ resultado é aumento ou diminuição nas vendas, dependendo de ter o preço de venda unitário aumentado ou diminuído.

c. Variação decorrente de alterações tanto no volume como no preço de venda unitário: uma vez que geralmente não ocorrem as hipóteses previstas em (a) e (b), elas são agora abandonadas. Multiplica-se, portanto, a variação no volume pela variação no preço de venda unitário. O resultado é aumento ou diminuição nas vendas. Haverá aumento se tanto o preço de venda como o volume tiverem aumentado; e diminuição se ambos tiverem caído; ocorrerá também diminuição se um dos dois (preço de venda unitário ou volume) tiver decrescido.

\section{Análise das variações no custo das mercadorias vendidas}

a. Variação decorrente de alteração no volume: é obtida supondo-se que não tenha havido alteração no custo unitário e multiplicando-se a variação no volume pelo custo unitário do ano anterior (ou uma média desses custos no ano). O resultado é aumento ou diminuição no custo das mercadorias vendidas, dependendo de ter o volume aumentado ou diminuído.

b. Variação decorrente de alteração no custo unitário: é obtida supondo-se que não tenha havido alteração no volume e multiplicando-se a variação no custo unitário pelo volume do ano anterior. O resultado é aumento ou diminuição no custo das mercadorias vendidas, dependendo de ter o custo unitário aumentado ou diminuído.

c. Variação decorrente de alterações tanto no volume como no custo unitário: uma vez que geralmente não ocorrem as hipóteses previstas em (a) e (b), elas são agora abandonadas. Multiplica-se, portanto, a variação no volume pela variação no custo unitário. O resultado é aumento ou diminuição no custo das mercadorias vendidas. Haverá aumento se tanto o custo como o volume tiverem aumentado; diminuição se ambos tiverem caído; e também diminuição se um dos dois (custo unitário ou volume) tiver decrescido.

Utilizando as informações da companhia Alfa, podemos agora obter o quadro 1, cujos resultados podem ser vistos nos gráficos 5 e 6 .

Percebe-se nitidamente nos gráficos 5 e 6 a influência das três variáveis não só na análise das variações das vendas como também na do custo das mercadorias vendidas, pois neles é visível o retângulo diferente que se refere a cada variável. É interessante, por isso mesmo, que se comparem os gráficos 5 e $6 \mathrm{com}$ os anteriores que haviam explicado a variação no lucro bruto sobre vendas em função de apenas duas variáveis.

No caso da Companhia Alfa, propositalmente simplificamos algumas questões, com a finalidade de facilitar a exposição do assunto e dar ênfase aos princípios do tipo de análise feita.

Vejamos, pois, dois casos um pouco mais complexos, em que a importância da análise com três variáveis será ainda mais destacada. 


\section{QUADRO 1}

\section{Demonstração da Análise das Variações no Lucro Bruto sobre Vendas (Companhia Alfa)}

1. ANÁLISE DAS VARIAÇÕES EM VENDAS

a. Variação decorrente de alteração no volume.

Se nẫo tivesse havido alteração no preço de venda unitário, teria ocorrido aumento nas vendas,

pois 2.500 (aumento no volume) $\times$ Cr\$ 100 (preço de venda unitário de 19x1) =

$\operatorname{cr} \$ 250.000$

b. Variação decorrente de alteração no preço de venda unitário.

Se nẫo tivesse havido alteração no volume, teria ocorrido aumento nas vendas, pois:

Cr\$ 20 (aumento no preço de venda unitário) $\times 10.000$ (volume do ano 19x1) =

200.000

c. Variação decorrente de alterações tanto no volume como no preço de venda unitário.

Diversamente do suposto em (a) e (b) acima, houve aumento tanto no volume como no preço de venda unitário, o que resultou em aumento de vendas, pois:

2.500 (aumento no volume) $\times$ Cr\$ 20 (aumento no preço de venda unitário) $=$

50.000

Aumento verificado nas vendas.

$\operatorname{Cr} \$ 500.000$

2. ANÁLISE DAS VARIAÇÕES NO CUSTO DAS MERCADORIAS VENDIDAS

a. Variação decorrente de alteração no volume.

Se nẩo tivesse havido alteraçã̃o no custo unitário, teria ocorrido aumento no custo das

mercadorias vendidas, pois: 2.500 (aumento no volume) $\times \mathrm{Cr} \$ 40$ (custo unitário de 19x1)

$\operatorname{Cr} \$ 100.000$

b. Variação decorrente de alteração no custo unitário.

Se nẵo tivesse havido alteração no volume, teria ocorrido aumento no custo das mercadorias

vendidas, pois: $\mathrm{Cr} \$ 40$ (aumento no custo unitário) $\times \mathrm{Cr} \$ 10.000$ (volume do ano 19x1) =

400.000

c. Variação decorrente de alterações tanto no volume como no custo unitário.

Diversamente do suposto em (a) e (b) acima, houve aumento tanto no volume como no

custo unitário, o que resultou em aumento no custo das mercadorias vendidas, pois

2.500 (aumento no volume) $\times$ Cr $\$ 40$ (aumento no custo unitário) =

100.000

Aumento verificado no custo das mercadorias vendidas.

Diminuição no lucro bruto sobre vendas.

600.000

Cr\$ 100.000

\section{CASO DA COMPANHIA BETA}

A companhia Beta apresenta as seguintes informações:

\begin{tabular}{|c|c|c|c|c|c|c|c|}
\hline & \multicolumn{2}{|c|}{$19 \times 1$} & \multicolumn{2}{|c|}{$19 \times 2$} & $\begin{array}{l}\text { Aumento (ou } \\
\text { diminuição) }\end{array}$ & $\begin{array}{l}\text { Aumento (ou } \\
\text { diminuição) }\end{array}$ & $\begin{array}{c}\text { Índice de } 19 \times 2 \mathrm{em} \\
\text { relação a 19X1 }\end{array}$ \\
\hline & $\operatorname{cr} \$$ & $\%$ & $\mathrm{Cr} \$$ & $\%$ & $\mathrm{Cr} \$$ & $\%$ & \\
\hline Vendas Líquidas & 1.000 .000 & 100 & 1.600 .000 & 100 & 600.000 & 60 & 1,6 \\
\hline $\begin{array}{l}\text { (-) Custos das Merca- } \\
\text { dorias Vendidas }\end{array}$ & 100.000 & 10 & 400.000 & 25 & 300.000 & 300 & 4,0 \\
\hline $\begin{array}{l}\text { Lucro Bruto } \\
\text { sobre Vendas }\end{array}$ & 900.000 & 90 & 1.200 .000 & 75 & 300.000 & 33 & 1,3 \\
\hline $\begin{array}{l}\text { Preço de Venda } \\
\text { Unitário }\end{array}$ & $\mathrm{Cr} \$ 100$ & & $\operatorname{Cr} \$ 200$ & & $\operatorname{Cr} \$ 100$ & $100 \%$ & 2,0 \\
\hline Unidades Vendidas & 10.000 & & 8.000 & & $(2.000)$ & (20) & 0,8 \\
\hline Custo Unitário & $\operatorname{Cr} \$ 10$ & & $\mathrm{Cr} \$ 50$ & & $\mathrm{Cr} \$ 40$ & $400 \%$ & 5,0 \\
\hline
\end{tabular}

Nessa empresa o lucro bruto sobre vendas aumentou $33 \%$ de um período para outro, embora as vendas tivessem crescido $60 \%$ e o custo das mercadorias vendidas $300 \%$ (sendo, em $19 \times 2,4,0$ vezes a quantia de $19 \times 1$ ). Todavia, o lucro bruto em relação às vendas em $19 \times 1$ era $90 \%$ e em $19 \times 2$ caiu para $75 \%$.

Nota-se que o preço de venda unitário elevou-se de um ano para outro, em 100\%, enquanto que o custo unitário aumentou $400 \%$ ! Além disso, foram vendidas apenas 8.000 unidades em 19x2, o que representa uma diminuição de $20 \%$ em relação a $19 \times 1$.

Os gráficos 7 e 8 permitem visualizar esses dados. 


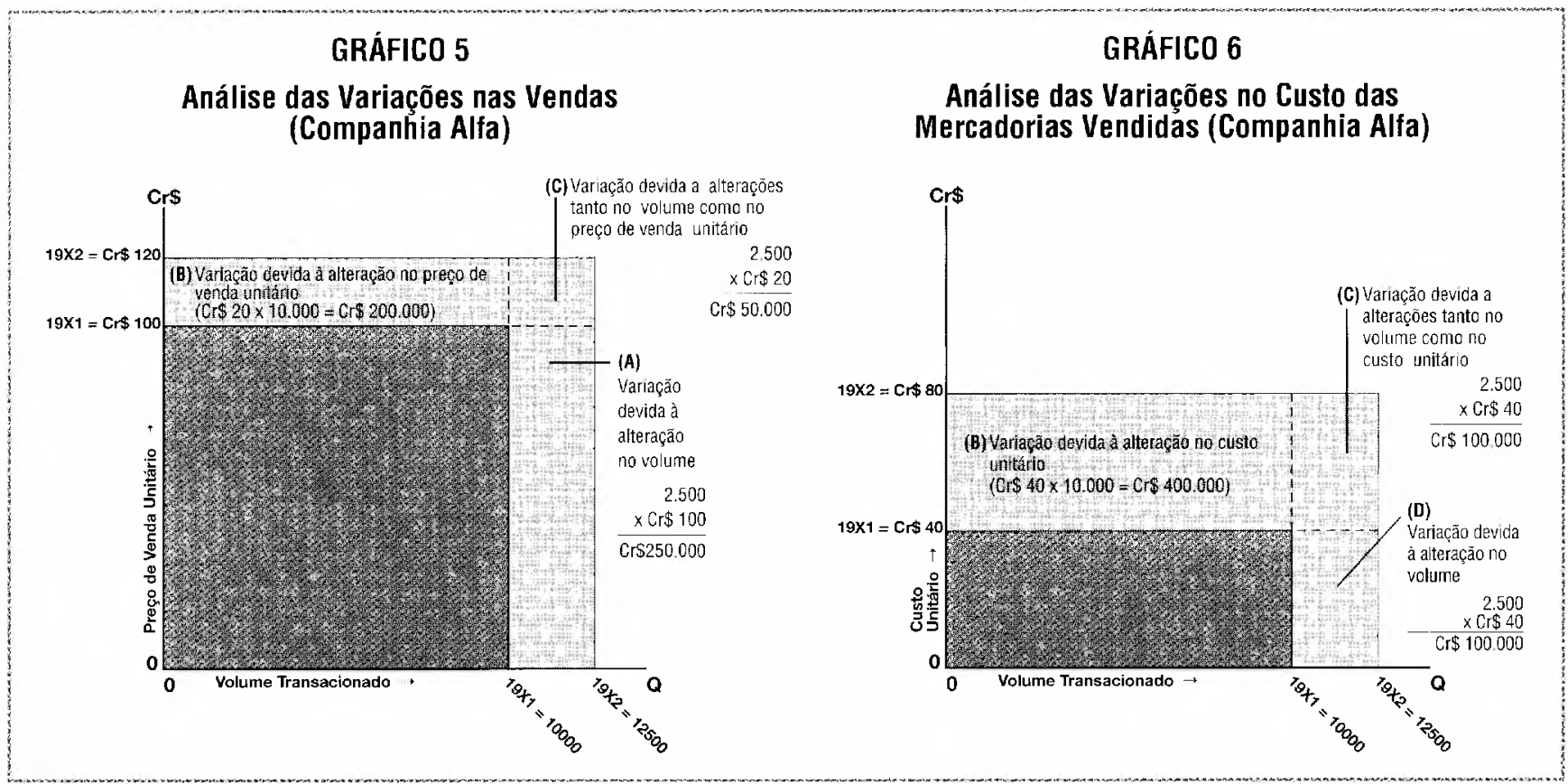

No gráfico 7 , percebe-se o efeito do aumento do preço de venda unitário e a diminuição no volume de unidades vendidas; no gráfico 8, a elevação brutal $(400 \%)$ do custo unitário e o efeito do menor volume de unidades transacionadas.

Seguindo os passos indicados na exposição do caso da Companhia Alfa, podemos obter o quadro 2.

Podemos expor, mais uma vez, o conteúdo desse tipo de demonstração $\mathrm{cm}$ gráficos, o que é feito nos gráficos 9 e 10.

O gráfico 9, que mostra a análise das variações nas vendas, contém o retângulo (A),

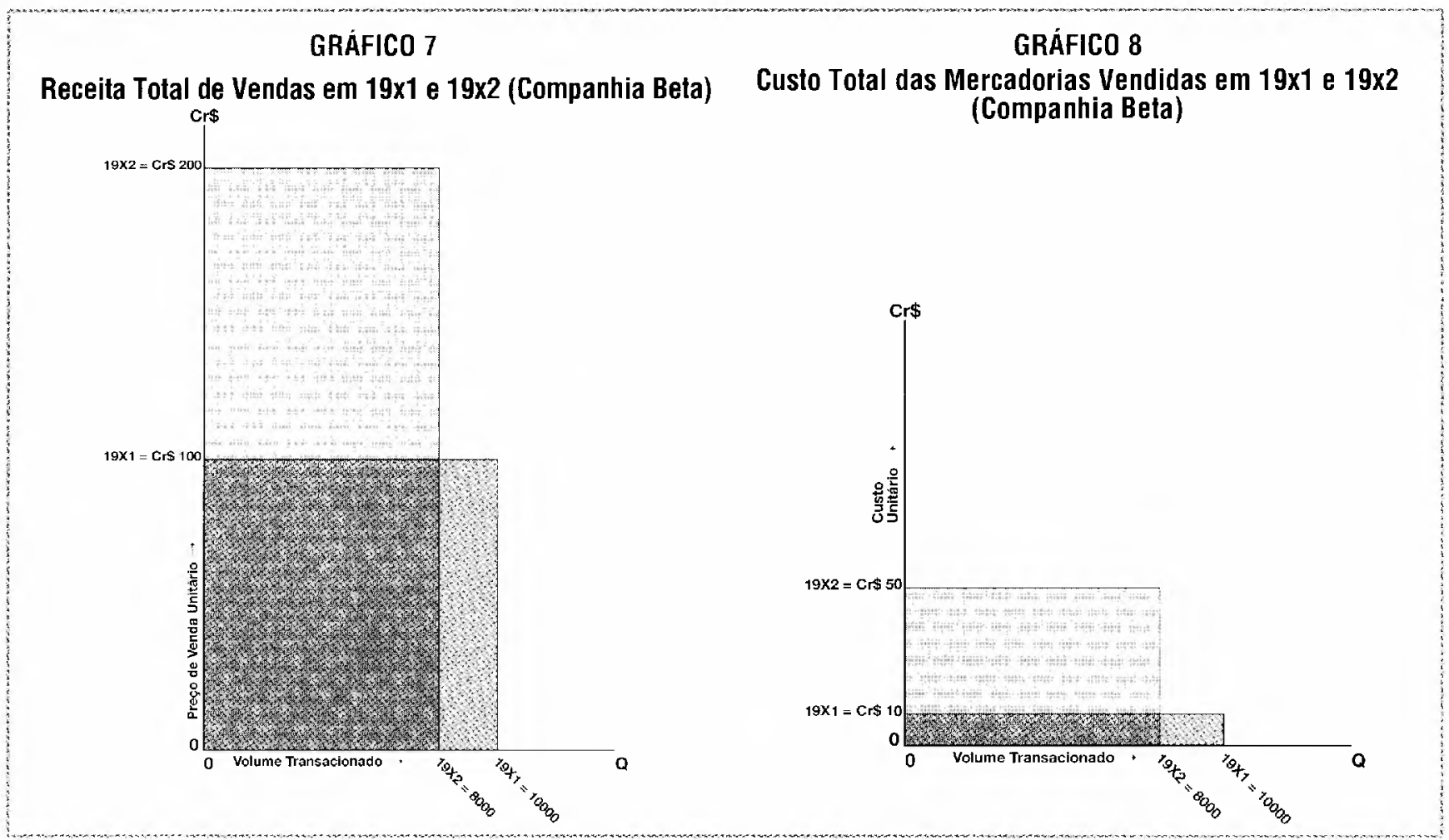




\section{QUADRO 2}

\section{Demonstração da Análise das Variações no Lucro Bruto sobre Vendas (Companhia Beta)}

\section{ANÁLISE DAS VARIAÇÕES EM VENDAS}

a. Variação decorrente de alteração no volume.

Se não tivesse havido alteração no preço de venda unitário, teria ocorrido diminuiç̧ão nas vendas, pois 2.000 (diminuição no volume) $\times$ Cr\$ 100 (preço de venda unitário de 19×1) =

$\operatorname{Cr} \$ 200.000$

b. Variação decorrente de alteração no preço de venda unitário.

Se não tivesse havido alteração no volume, teria ocorrido aumento nas vendas, pois:

Cr\$100 (aumento no preço de venda unitário) $\times 10.000$ (volume do ano $19 \times 1$ ) $=$.

$\frac{1.000 .000}{\operatorname{Cr} \$ 800.000}$

Diferença.

200.000

c. Variação decorrente de alterações tanto no volume como no preço de venda unitário.

Diversamente do suposto em (a) e (b) acima, houve diminuição no volume e aumento

no preço de venda unitário, o que resultou em diminuição de vendas, pois:

2.000 (diminuição no volume) $\times \mathrm{Cr} \$ 100$ (aumento no preço de venda unitário) $=$

Aumento verificado nas vendas.

2. ANÁLISE DAS VARIAÇŌES NO CUSTO DAS MERCADORIAS VENDIDAS

a. Variação decorrente de alteração no volume.

Se não tivesse havido alteração no custo unitário, teria ocorrido diminuição no custo das

mercadorias vendidas, pois: 2.000 (diminuição no volume) $\times \operatorname{Cr} \$ 10$ (custo unitário de 19x1) =

$\operatorname{Cr} \$ 20.000$

b. Variação decorrente de alteração no custo unitário.

Se năo tivesse havido alteração no volume, teria ocorrido aumento no custo das mercadorias

vendidas, pois: Cr\$ 40 (aumento no custo unitário) $\times 10.000$ (Volume do ano 19×1) =

$\operatorname{Cr} \$ 380.000$

Diferença

c. Variação decorrente de alterações tanto no volume como no custo unitário.

Diversamente do suposto em (a) e (b) acima, houve diminuição no volume e aumento no

custo unitário, o que resultou em diminuição no custo das mercadorias vendidas, pois

2.000 (diminuição no volume) $\times \mathrm{Cr} \$ 40$ (aumento no custo unitário) $=$

Aumento verificado no custo das mercadorias vendidas

Diminuição no lucro bruto sobre vendas

300.000

$\operatorname{Cr} \$ 300.000$

representando a variação decorrente de alteração no volume de mercadorias se não houvesse alteração no preço de venda unitário; o retângulo (B), que compreende o retângulo $(C)$ e mostra o efeito que o aumento do preço de venda unitário teria sobre a receita total de vendas se não ocorresse alteração no volume de mercadorias vendidas; e, finalmente, o retângulo (C), contido no retângulo (B), representando o efeito da diminuição no volume de mercadorias vendidas sobre o aumento no preço de venda unitário, ou seja, quanto se poderia ganhar a mais nas vendas se não diminuísse o volume de mercadorias transacionadas.

Observando-se o gráfico 10, que demonstra a análise das variações no custo das mercadorias vendidas, podemos perceber o retângulo (A), que representa a variação decorrente de alteração no volume de mercadorias se não tivesse havido uma alteração no custo unitário; o retângulo (B), que contém o retângulo (C), mostrando o efeito do aumento do custo unitário sobre o custo total das mercadorias vendidas se não ocorresse alteração no volume de mercadorias vendidas e, por fim, o retângulo (C), contido no retângulo (B), representando o efeito da diminuição no volume de mercadorias vendidas sobre o aumento no custo unitário, isto é, quanto o custo total das mercadorias vendidas seria maior se não fosse reduzido o volume de mercadorias transacionadas.

Com isso, podemos afirmar que a interpretação da solução para o caso da companhia Beta é bem mais complexa do que a da companhia Alfa. (Para verificá-lo, basta comparar os dois últimos gráficos com os gráficos 5 e 6.) Mas, ainda assim, foi possível, pelo procedimento adotado, determinar por que e como variou o lucro bruto sobre vendas da Companhia Beta. 


\section{CASO DA COMPANHIA GAMA}

A Companhia Gama apresenta alguns aspectos diferentes dos anteriormente vistos, pois as informações apresentadas por ela são:

\begin{tabular}{|c|c|c|c|c|c|c|c|}
\hline & \multicolumn{2}{|c|}{$19 \times 1$} & \multicolumn{2}{|l|}{$19 \times 2$} & $\begin{array}{l}\text { Aumento (ou } \\
\text { diminuicão) }\end{array}$ & $\begin{array}{l}\text { Aumento (ou } \\
\text { diminuicăo) }\end{array}$ & $\begin{array}{c}\text { Indice de } 19 \times 2 \mathrm{em} \\
\text { relacão a } 19 \times 1\end{array}$ \\
\hline & $\mathrm{Cr} \$$ & $\%$ & $\mathrm{Cr} \$$ & $\%$ & $\operatorname{Cr} \$$ & $\%$ & \\
\hline Vendas Líquidas & 1.000 .000 & 100 & 600.000 & 100 & $(400.000)$ & $(40)$ & 0,6 \\
\hline $\begin{array}{l}\text { (-) Custos das Merca- } \\
\text { dorias Vendidas }\end{array}$ & 300.000 & 30 & 100.000 & 17 & $(200.000)$ & (67) & 0,3 \\
\hline $\begin{array}{l}\text { Lucro Bruto } \\
\text { sobre Vendas }\end{array}$ & 700.000 & 70 & 500.000 & 83 & $(200.000)$ & (29) & 0,7 \\
\hline $\begin{array}{l}\text { Preço de Venda } \\
\text { Unitário }\end{array}$ & $\operatorname{CrS} 100$ & & $\operatorname{Cr} \$ 120$ & & $\operatorname{Cr} \$ 20$ & $20 \%$ & 1,2 \\
\hline Unidades Vendidas & 10.000 & & 5.000 & & $(5.000)$ & $(50) \%$ & 0,5 \\
\hline Custo Unitário & $\mathrm{Cr} \$ 30$ & & $\operatorname{Cr} \$ 20$ & & Crs (10) & $(33) \%$ & 0,7 \\
\hline
\end{tabular}

Houve diminuição de $29 \%$ no lucro bruto sobre vendas de um período para outro, embora as vendas tivessem diminuído $40 \%$ e o custo das mercadorias vendidas $67 \%$. O lucro bruto sobre vendas em $19 \times 1$ era de $70 \%$ e em 19x2 elevou-se para $83 \%$.

Observe-se que o preço de venda unitário elevou-se, de um ano para outro, em $20 \%$, enquanto que o custo unitário foi reduzido em 33\%! Essa política da empresa resultou em diminuição de 5.000 unidades (50\%) em 19x2 em relação a 19x1.

Os gráficos 11 e 12 mostram a situação da companhia Gama no tocante à receita total de vendas $\mathrm{c}$ ao custo total das mercadorias vendidas em 19x1 e 19x2.

Nota-se quão diferentes são os dados da companhia Gama em relação às empresas anteriores. Isso é bem realçado nos dois últimos gráficos citados, especialmente o gráfico 12.

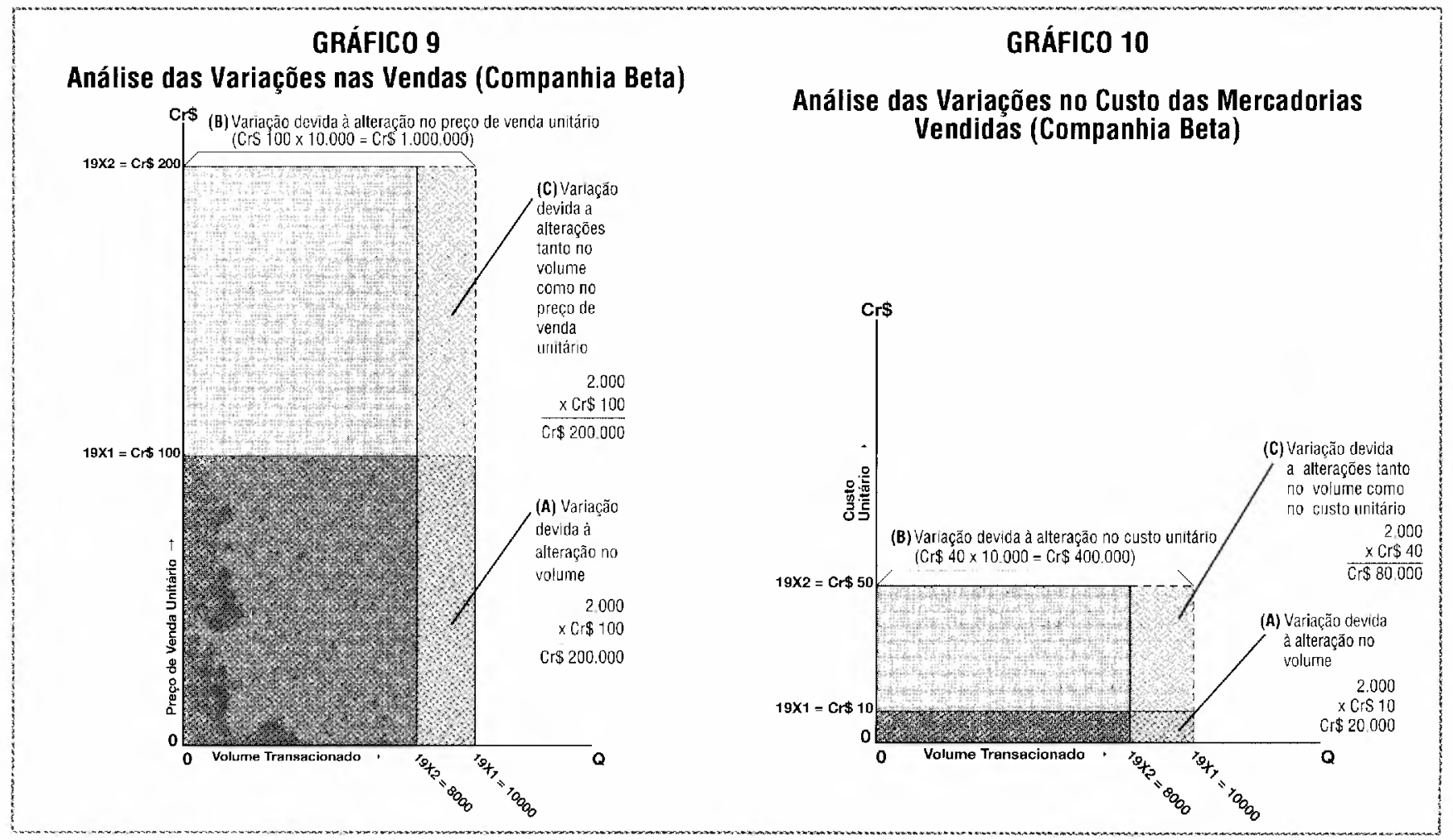




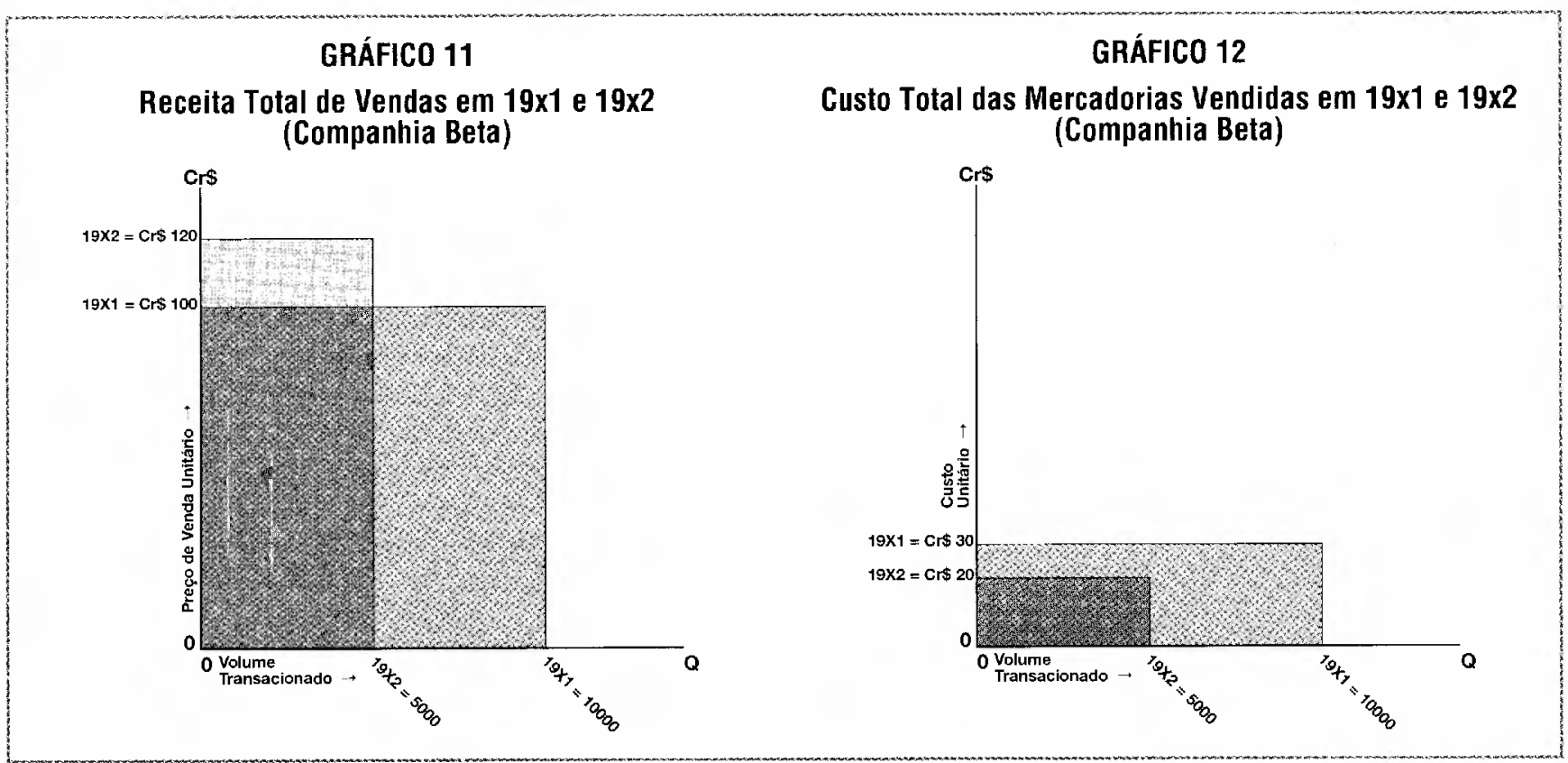

No quadro 3, damos a explicação da variação ocorrida no lucro bruto sobre vendas da Companhia Gama.

No gráfico 13, encontramos o retângulo (A), que representa a variação decorrente da alteração no volume de mercadorias se não houvesse alteração no preço de venda unitário; o retângulo (B), que compreende o retângulo (C) e mostra o efeito que o aumento do preço de venda unitário teria sobre a receita total de vendas sc não ocorresse alteração no volume de mercadorias vendidas; e, finalmente, o retângulo (C), contido no retângulo (B), que representa o efeito da diminuição no volume de mercadorias vendidas sobre o aumento no preço de venda unitário, ou seja, quanto se poderia ganhar a mais nas vendas se não fosse reduzido o volume de mercadorias transacionadas.

O gráfico 14 mostra a análise das variações no custo das mercadorias vendidas.

Notamos no gráfico 14 o retângulo (A), que compreende metade do retângulo (B) e todo retângulo $(\mathrm{C})$ e representa a variação decorrente de alteração no volume de mercadorias, se não houvesse alteração no custo unitário; o retângulo (B), que contém o retângulo (C) e mostra o efeito da diminuição do custo unitário sobre o custo total das mercadorias vendidas, se não ocorresse alteração no volume de mercadorias vendidas, e, por fim, o retângulo (C), contido no retângulo (B), que representa o efeito da diminuição no volume de mercadorias vendidas sobre a diminuição no custo unitário, isto é, quanto o custo total das mercadorias vendidas seria maior se não fosse reduzido o volume de mercadorias transacionadas.

\section{RESUMO E CONCLUSÕES}

A análise das variações no lucro bruto sobre vendas pode ser feita - como no caso da compa-

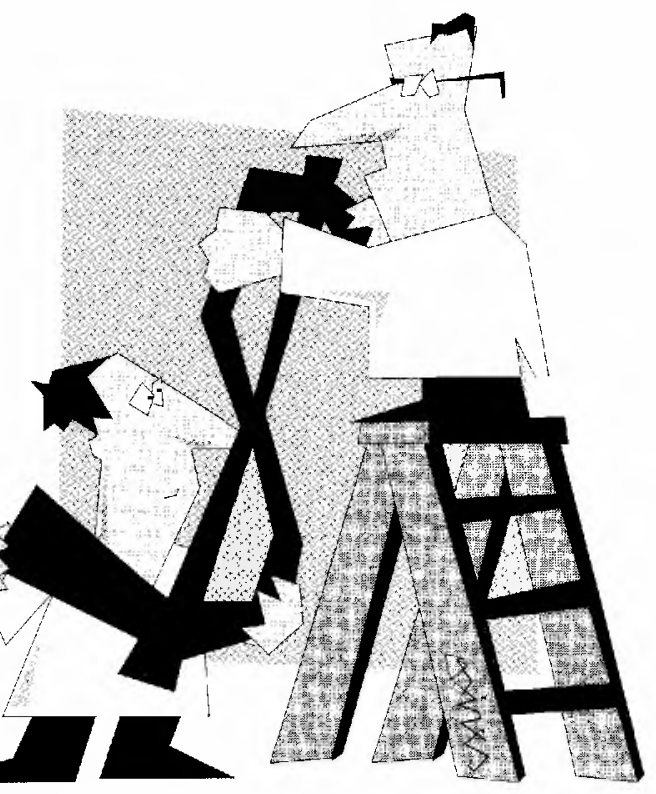




\section{QUADRO 3}

\section{Demonstração da Análise das Variações no Lucro Bruto sobre Vendas (Companhia Gama)}

\section{ANÁLISE DAS VARIAÇÕES EM VENDAS}

a. Variação decorrente de alteração no volume. Se não tivesse havido alteração no preço de venda unitário, teria ocorrido diminuição nas vendas, pois 5.000 (diminuição do volume) $\times$ Cr\$ 100 (preço de venda unitário de 19x1) =

b. Variação decorrente de alteração no preço de venda unitário. Se não tivesse havido alteração no volume, teria ocorrido aumento nas vendas, pois: Cr\$20 (aumento no preço de venda unitário) x 10.000 (volume do ano $19 \times 1$ ) =

Diferença.

$\frac{200.000}{\operatorname{Cr} \$ 300.000}$

c. Variação decorrente de alterações tanto no volume como no preço de venda unitário. Diversamente do suposto em (a) e (b) acima, houve diminuição no volume e aumento no preço de venda unitário, o que resultou em diminuição de vendas, pois:

5.000 (diminuição no volume) $\times \operatorname{Cr} \$ 20$ (aumento no preço de venda unitário) $=$

100.000

Diminuição verificada nas vendas.

\section{ANÁLISE DAS VARIAÇÕES NO CUSTO DAS MERCADORIAS VENDIDAS}

a. Variação decorrente de alteração no volume. Se nẩo tivesse havido alteração no custo unitário, teria ocorrido diminuição no custo das mercadorias vendidas, pois: 5.000 (diminuição no volume) $\times \mathrm{Cr} \$ 20$ (custo unitário de $19 \times 1$ ) $=$

b. Variação decorrente de alteração no custo unitário. Se não tivesse havido alteração no volume, teria ocorrido diminuição no custo das mercadorias vendidas, pois: $\mathrm{Cr} \$ 10$ (diminuição no custo unitário) x 10.000 (volume do ano 19x1) =

c. Variação decorrente de alterações tanto no volume como no custo unitário.

Diversamente do suposto em (a) e (b) acima, houve diminuição tanto no volume como no custo unitário, 0 que resultou em diminuição no custo das mercadorias vendidas, pois 5.000 (diminuição no volume) $\times \mathrm{Cr} \$ 10$ (diminuição no custo unitário) $=$

nhia Alfa - em função da análise horizontal e vertical tradicional, acrescida de dados sobre o preço e custo unitários, volume de unidades vendidas e mark-up sobre o custo. Todavia, a explicação obtida mediante o emprego desses instrumentos não só é, freqüentemente, bastante complicada, como também não esclarece de todo a questão.

Realizamos, portanto, a análise com duas variáveis - volume e preço unitário para as vendas, volume e custo unitário para o custo das mercadorias vendidas com explicação gráfica inclusive (gráficos 3 e 4). Ainda assim, essa solução para o problema não é satisfatória, pois não leva em consideração outra importante informação: a variação decorrente de alterações tanto no volume como no preço de venda unitário - no caso da análise das vendas - ou no custo unitário - no caso da análise do custo das mercadorias vendidas.

Fizemos, então, uma demonstração com três variáveis (quadro 1) e mostramos graficamente a solução obtida (gráficos 5 e 6).

Para mostrar a aplicação dessa análise com três variáveis em situações mais complexas, foram descritos e solucionados os casos das empresas Beta e Gama, conforme indicam o quadro 2 e os gráficos 9 e 10, e o quadro 3 e os gráficos 13 e 14, respectivamente.

As soluções apresentadas nessas ilustrações podem ser adaptadas a outras empresas, conforme a oportunidade, sendo possível simplificá-las, embora preferível que sejam explicativas e venham acompanhadas de gráficos.

A análise com três variáveis para explicar por que e como o lucro bruto sobre vendas variou de um período para outro assemelha-se, em muitos aspectos, com o processo de análise e controle realizado no processo orçamentário - quando se es- 


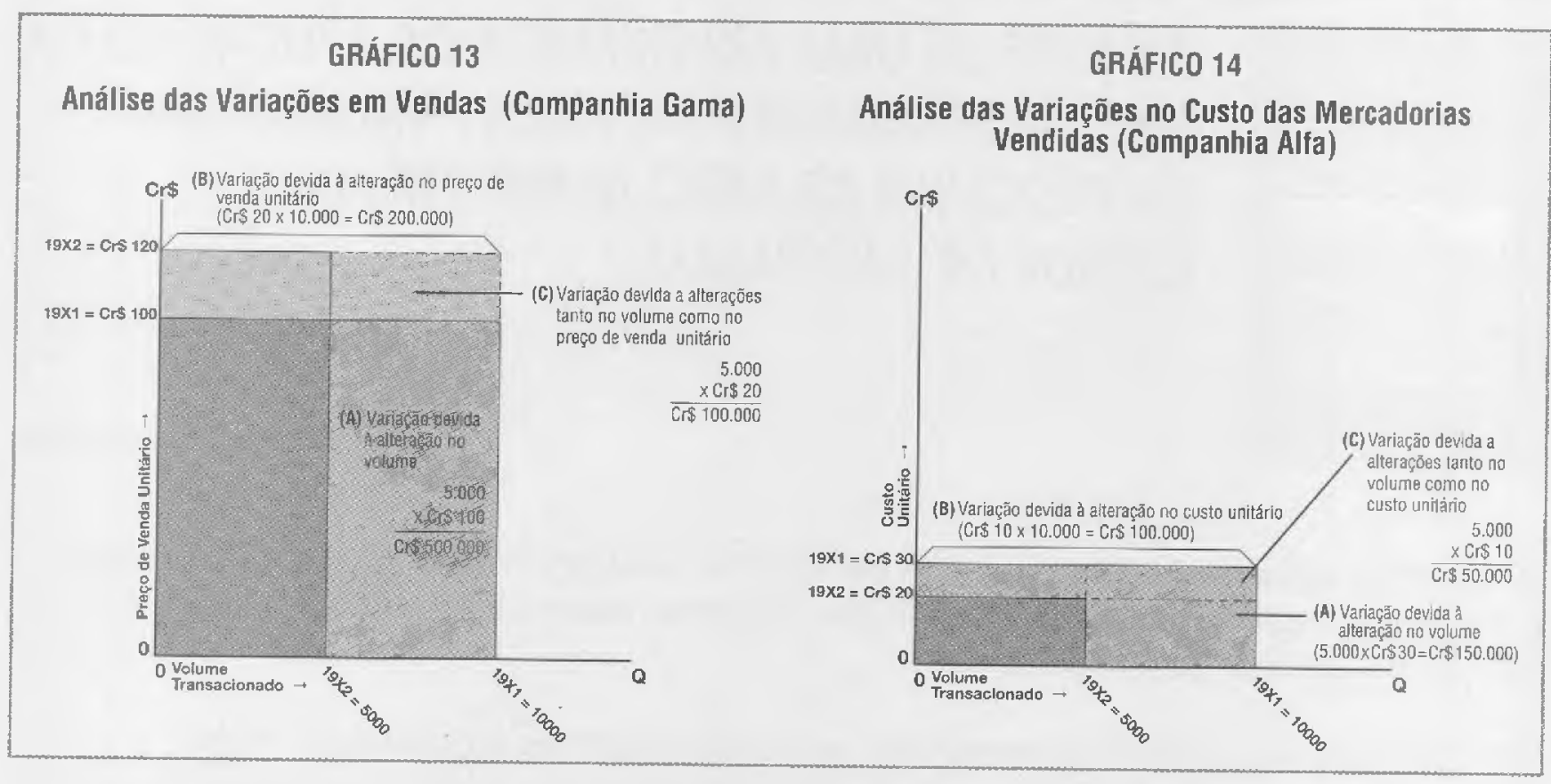

tudam as diferenças entre o padrão orçado e os dados reais - e com o processo de análise e controle das variâncias, nos sistemas de contabilidade de custo-padrão (standard), como devem ter percebido os estudiosos desses ramos de especialização da administração contábil e financeira.

Embora útil, a análise das variações no lucro bruto sobre vendas deve ser interpretada com certo cuidado, pois não pretende mostrar o efeito da mudança de preços sobre o volume de mercadorias transacionadas.

O cálculo do efeito de volume, preço unitário e custo unitário está baseado na premissa de que cada um deles aja independentemente. Ora, essa premissa não é inteiramente cxata, pois existe inter-relação entre vendas, custo e volume, à medida que afetam o lucro bruto sobre vendas.

Os casos ilustrados não significam que tenhamos tomado posição neste artigo a favor de "vender pouco e caro" ou "vender muito e barato".

Finalmente, devemos deixar claro que propositalmente demos exemplos de três empresas diferentes, cada uma delas operando com um só produto. Mas nada impede que as ilustrações sirvam para análise de mais produtos (ou mais linhas de mercadorias) de uma só empresa. Para isso bastará que tenhamos dados globais sobre vendas, custo das mercadorias vendidas e lucro bruto sobre vendas e que esses dados sejam desdobrados por produto (ou linha).

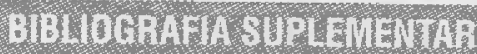

BACKER, M. , JACOBSEN, L. E. Cost accouting, a managerial approach. New York: McGraw Hill, 1964.

- EASTON, E. E., NEWTON, B . L. Accounting and the analysis of financial data. New York: McGraw-Hill, 1958.

- FINNEY, H. A., MILLER. H. E. Principles of accounting, intermediate. 6 ed. Englewood Cliffs: Prentice-Hall, 1965.

- HOLMES, A. W. MAYNARD, G. P. EDWAROS, J. D. MEIER, R A in termediate accounting. 3. ed. Homewood: Richard D. Irwin, 1958.

- HASEMAN, W. C. Management uses of accounting. Boston: Allyn and Bacon, 1963.

- JOHNSON, A. W. Intermediate accounting. Edição revista. New York: Holt Rinehart and Windston, 1961.
- KENNEDY, R. D., McMULLEN, S. Y. Financial statements, forms, analysis and interpretation. 4. ed. Homewod: Richard D. Irwin, 1962.

- MATZ, A., CURRY, O. J., FRANK, W. Cost accounting, management's operational tool for planning, Control and Analysis. Cincinatti: South Western, 1962

- MOYER, C. A., MAUTZ, R. K. Functional accounting, intermediatc. 2. ed. New York: John Wiley \& Sons, 1951.

- MYER, J. N. Financial statement analysis. Principles and techniques. Englewood Cliffs: Prentice Hall, 1961.

- WELSCH, G. A., ZLATKOVICH, C. T., WHITE, J. A. Intermediate accounting. Homewood: Richard D. Irwin, 1963. 